\title{
The Use of the Digital "Vorarlberg Atlas" in the Subject of Geography and Economics: Experiences from a School Project
}

\author{
Martin Dür \\ PH Vorarlberg, Feldkirch/Austria·martin.duer@ph-vorarlberg.ac.at \\ Full paper double blind review
}

\begin{abstract}
The purpose of this project is to show various possibilities for the use of WebGIS applications, when dealing with regional questions arising in the school subject of Geography and Economics. By using digital atlases of the Austrian provinces - WebGIS applications run by regional province administrations - students acquire various key competences: they encounter comprehensive geographic methods by working with maps and statistics, and they develop soft skills such as critically reflecting and interpreting data provided by the largest source of regional geodata of their federal state. In the following class project, the students collect their own data and use the provincial digital atlases to portray the results in thematic maps. In addition to the many possibilities these atlases offer, difficulties using this approach in the classroom will also be discussed.

Through the creation of an "emotional space map" students learn that their own evaluation of space, and their spatial behavior is not simply constructed by objective criteria, but is influenced by personal conduct and spatial perception. In their search for possible suggestions to improve a city's image, students recognize the impact each individual's conduct has on the quality of life, and learn that there is no simple way of resolving the numerous emerging problems.
\end{abstract}

\section{Introduction}

Personal motivation for this project includes the new requirements of the competency oriented final exams, and the creation and presentation of a research paper ("Vorwissenschaftliche Arbeit"). This project intends to meet the challenge of improving geographical methodological competence of students presently in lower forms.

For this purpose a project was conducted over the course of three months in the summer semester of 2014, in the $8^{\text {th }}$ grade in the subject Geography and Economics. The focus of the ten lessons was data collection and evaluation, as well as map construction with the use of a web-based Geographic Information System (WebGIS), and a critical reflection of the results. At the end of the project, the students had the possibility of presenting their results and their subjective perception of the quality of life in the inner city of Feldkirch, in connection with personal suggestions for improvement to local politicians and civil servants.

GI_Forum - Journal for Journal for Geographic Information Science, 1-2015.

(C) Herbert Wichmann Verlag, VDE VERLAG GMBH, Berlin/Offenbach. ISBN 978-3-87907-558-4.

(C) ÖAW Verlag, Wien. ISSN 2308-1708, doi:10.1553/giscience2015s335. 
In spite of numerous hours spent by students behind a computer, many of them show a deficit in their skills using standard software such as Microsoft Excel. Working on a goaloriented task with a Geographic Information System (GIS) is a new experience for almost all students. The prevailing expectation that all students nowadays possess comprehensive skills using digital tools is unfortunately not the case. Due to the increasing use of geomedia (GM) (digital globes, GPS navigation and location based services) in everyday life, modern education should teach the relevant skills to use these tools in a productive way. In the context of a rapidly increasing amount of free access to geodata, and the possibilities for the user to acquire spatial data, it is apparent that education in Geography and Economics needs to create practice-oriented tasks in order to strengthen these competencies. The following project will show that professional WebGIS applications, as used by province and township governments, can also be used in classroom and school education, and do not have to be restricted to programs like Google Earth. For the use of Google Earth in the subject Geography and Economics, see e.g. SITTE (2008).

To achieve a high level of independent learning, the discovery-research method is the educational basis by which students individually work through tasks with the purpose of coming to conclusions as per scientific methods. Furthermore, the realization of this goal is thematically linked with the students' everyday life.

\section{Project Scope and Theoretical Approach}

The students are given the task of evaluating the inner city of Feldkirch (a town with approx. 31.000 inhabitants) according to their own "factor of well-being", as well as to investigate the average frequency with which they are present within these spaces. From the collected data using a WebGIS application, both a map showing the average statistical frequency of student presence in these areas, and a map showing the subjective average emotional perception of space using a four level scale are produced. To ensure that the task is not exclusively used as a technical exercise, the resulting maps are analyzed, and suggestions for improvements concerning the "factor of well-being" for certain city sections are collected and interpreted. Finally, thanks to the Feldkirch city government, students are given the chance to present their results to city officials.

Within the framework of this project, students use standard programs like Microsoft Excel or Google Drive, in combination with the web-based GIS "Vorarlberg Atlas" (vogis.cnv.at/ atlas/init.aspx). In addition to recent (from the year 2012) and historical aerial photos (from as early as the 1930s), there is a variety of geodata available that offers a qualitative advantage to Google Earth. For example under the topic "Planung und Kataster" ("planning and land register"; used in this school project) one does not only find aerial photos, but also a layer with the property and building boundaries, the land use, or information in the case of solar use. Comprehensive data in the "Vorarlberg Atlas" regarding the entire province are always available using uniform data, and the aerial photos are updated in cycles of every three years.

The students working with the "Vorarlberg Atlas" are therefore able to access a vast pool of data of the province. Using simple tools (lines and polygons), students can apply their collected data and create their own simple thematic maps. This type of WebGIS application exists in all Austrian provinces, but they do not all contain the same spectrum of available 
geodata or the same possibilities of interactivity. The same web-viewer used in the province of Vorarlberg is also used by the provinces of Styria, Carinthia, Salzburg, as well as Lower and Upper Austria. As an alternative, the project "Geoland.at" can be used for more general, Austrian-wide topics, as it provides access to the aerial photos of all the Austrian provinces. However, the scope of the available data is limited in comparison to the data offered by each of the provincial atlases (cf. SCHERIAU 2007). Generally speaking, one can see a dynamic development over the past years, which is accompanied with a rapidly growing number of freely available geodata. This development should not be excluded from the subject of Geography and Economics in order to convey the necessary basic competencies. The skill to work with digital GM can be seen as a new cultural capacity, which will be fundamental in successful geographical education (cf. KANWISCHER 2014). The so-called "spatial citizen" has the knowledge to take part in spatial decisions with the help of digital GM, and can use these skills to act in a democratic process. Due to the importance for every citizen, spatial citizen education should already take place at primary and secondary school level (cf. GRYL \& JEKEL 2012).

In addition to the improvement of digital competencies regarding the use of WebGIS applications, as well as data collection and processing software, this project requires that students reflect on their own subjective spatial and emotional awareness of the city. Personal emotions regarding space are conveyed in modern media through a variety of public channels, and can influence the conduct of others. For example, when digital maps contain a variety of geotags with tourist information about a certain region, this region will become more attractive to potential visitors. On the other hand, regions that contain negative feedback or are not commented might be avoided (for the possibilities of the use of geotagging in class cf. HERMES et al. 2011). Through the extended use of new technological devices with a permanent mobile connection to the Internet like smartphones or tablets, geotagging is often neither a manual nor conscious process. Geotagging happens automatically, e.g. by sending geocoded tweets. Needless to say, companies like Google are highly interested in location-based data. Every user of GM based applications helps companies like Google to extend this database (BOECKLER 2014). While e.g. the responsibility for making a tourist destination attractive used to fall exclusively in the hands of local tourist bureaus, which portrayed their region in the most positive light through various media channels, it now depends on the ratings and experiences assigned by tourists themselves. Geospatial information provided by volunteer contributors, however, is based on subjective emotions and perception of space, that nonetheless influence consumers without the quality of this information even being verified (c.f. Coleman et al. 2009). In this context, GRAHAM \& ZOOK $(2014,19)$ use the term "Augmented Realities" to describe the influence of digital geodata on our spatial experiences.

New technological innovations also enable non-professionals to create their own cartographic forms, often without any basic knowledge of cartographic standards, and create a parallel world to traditional cartography (cf. BUCHROITHNER \& GARTNER 2013). In this context TURNER (2006) suggested the term "neogeography" to describe the process of nonprofessionals collecting geodata, creating individual maps with web mapping tools and sharing these maps, as well as the connected data worldwide via Web 2.0-based applications. These "produsers" (cf. COLEMAN et al. 2009) are both users and producers of geospatial information. 
Working with GIS can also play an important role in education for sustainability. With the help of GIS, the relationship among different attributes (e.g. climatic change and flooding) can be explored, issues that cut across regions (e.g. water pollution) can be examined and changes over time can be monitored. Sustainability challenges can be explored, visualized and analyzed by the students (cf. HWANG 2013). In the same way spatial distribution of social disparities can be examined with the help of GIS based maps (cf. BORZNER 2013).

In recent years there has been a vast array of research projects done on the topic of emotional mapping. The "Fear Maps" of the US cities such as LA are one example (cf. MATEI et al. 2001). In Austria, the goal of the project "EmoMap", carried out by the Institute for Cartography in Vienna, is to record subjective spatial perception via a mobile App that generates a publically available map. The obtained results are used for route calculations of navigation systems that take pedestrians into account (cf. SCHMIDT \& KLETTNER 2012). The British artist Nold attempted through many projects to make subjective emotions measurable through technological means. In addition, Biometric Data and GPS Data of defined spaces, based on the movement of Pedestrian test subjects, are included in his studies. These sources deliver objective information of the emotional condition of test subjects and can also be used as a basis for spatial planning considerations (cf. NOLD 2009). OBERRAUCH \& KELLER (2015) organized a school project in Innsbruck in which students mapped locations near their school where they feel comfortable, as well as places they don't like with the help of the web application "Scribble Maps" by using green and red pins. In a second step, the individual pins from all the students were put together in one "emotional map". This map formed the basis for a deeper examination of different areas.

Within the school project described in this article, all places of a defined area are rated by the students according to their own "factor of well-being" and the average frequency with which they are present within these spaces is elevated. Students can discover that their subjective spatial perception influences their own personal conduct. Which spaces routinely invite one to frequent them during the lunch break or after school? Which spaces are avoided at all costs or stays are kept as short as possible? And which spaces, although they are assessed as pleasant, are, however, not visited because they are situated too far away?

In creating a subjective map to convey personal and emotional spatial perception, students discover not only that maps are not purely objective modes of portrayal for spatial content, but rather that maps are always an expression of a certain point of view and world perception - their impression decidedly influences their design. Maps are "keine Abbilder der Welt, sondern visualisieren spezifische Perspektiven auf sie "(not portrayals of the world, but rather visualizations of specific perspectives of it) (GRYL 2010, 20). Therefore they always portray a fabricated image of reality (cf. MAREK 2009) and can be seen as "visual arguments and stories" (PRESNER et al. 2014, 15).

With the following description of the project sequence, a possible use of the Austrian digital province atlases in the subject of Geography and Economics will be shown. 


\section{Implementation of the Project}

\subsection{Pre Considerations - Orientation and Definition of the Research Field}

At the beginning of the project, attributes students associate with spaces both pleasant and unpleasant are collected in a class brainstorming session. These ideas are then compiled with the help of two mind maps. For students, negative spaces include dark underpasses and dirty alleys or places with the presence of peripheral social groups. It could be the small group of men drinking alcohol that usually hangs out on the right hand sidewalk next to the river - a path that is easily avoidable - or in the past two to three years the rising number of beggars of East-European origin present in the shopping streets that students see as a new phenomenon. This immediate confrontation leads students to conclude that "it is no longer possible to enjoy peace and quiet in public spaces without being disturbed" (original quote of one student, translated into English). Social periphery groups in public spaces are seen as "unwelcome subjects" and the solution being the promotion of measures for a general ban on begging dominates the viewpoints of 14-year olds on this topic. At no point in the student discussion any consideration was given to the personal background of these groups, or what these public spaces mean from their perspective. The possible solutions students suggested were limited to restricting public space for socially marginalized groups. This lack of a multiperspective view was a reason to deal with this topic in the classroom at the end of the described project.

After the outer boundaries of the study area are defined, students use aerial photos as a basis for collectively dividing the city center into 55 investigation fields. Investigation fields are defined by streets and public squares, which the students see as a cohesive unit. This is the basis for each student's further work.

\subsection{Data Survey and Collection}

For the following step the students are given worksheets with detailed instructions in order to allow individual work pace. Over the course of four weeks, in their free time, as well as on a walk together through the sections of the city center, students record their frequency of presence in the investigation fields, as well as their own personal "factor of well-being". The compiled data is then processed by the students at home, using two premade templates prepared by the teacher in the online office program Google Drive. With Google Drive it is possible for multiple students to simultaneously work on a table, as every user receives continuously updated, synchronized data.

For each investigation field, the average of the personal "factor of well-being" and the average weekly presence of all 23 students is used in the final creation of the thematic maps.

\subsection{Depiction of the Results in Map Form}

At the beginning of this phase, students receive information about color selection in thematic maps to raise their awareness that even the selection of colors can influence certain associations (cf. MAREK 2009). Nonetheless, the teacher sets no limitations on color selection, leaving students room for creativity. Additionally, the intervals for the four (topic "factor of 
well-being") or rather five grades (topic "frequency of presence") are set collectively in class. (cf. Figure 2)

In groups of twos the students are given the task of creating a map on the topic of the "factor of well-being" and "frequency of presence" using the Vorarlberg Atlas. For students accustomed to working in a less structured manner, the creation of these maps is a big challenge. If a polygon is drawn once, it is possible to change the color but not the outline or the position. At this point, the polygon must be completely deleted. The polygons and the lettering or lines are numbered by the web-viewer according to their sequence of entry. If a polygon is deleted or its color needs to be changed, one must painstakingly search the number of the polygon entry in the toolbox menu.

The possibility of giving polygon entries own names in order to find an entry more quickly is unfortunately not an option. While this is not a problem with a small number of mapped areas, it often leads to long searches in our school project, which consists of 55 areas. Therefore, a well-planned procedure is necessary in order to reach usable results within a reasonable time. The creation of thematic maps is not the intended use of the Vorarlberg Atlas.
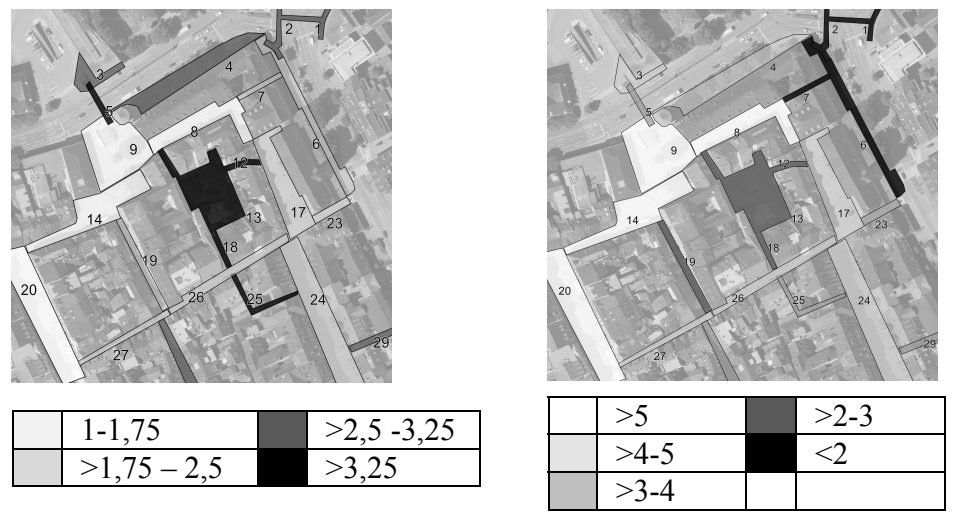

Fig. 1: Part of the developed maps, changed to black and white by the author.

Left: Emotional map. A value of 1 was assigned to areas that are especially agreeable and a value of 4 refers to areas considered very uncomfortable.

Right: Average weekly frequency of presence over a time span of 4 weeks

For this purpose, professional desktop GIS programs like for example QGIS or ArcGIS would be appropriate. Because these programs have a vast spectrum of functions, their use in school is only appropriate for special circumstances (e.g. in elective subjects). Otherwise Geography and Economics classes would be restricted to a computer science class, and the topical focus would be superseded by the technical focus (c.f. KANWISCHER 2014). Nonetheless, the creation of one's own map by using lines and areas or extra lettering provides an incomparably higher gain in knowledge than simply using a finished map product.

For the use in the classroom, simpler variations exist to create thematic maps from the basis of aerial photos. A study by HENNING \& VoGLER (2011) show the web-mapping tool Scribble-Maps as the highest rated. In this program, the aerial photos from Google Earth are used as a basis, and allow work on topics all over of the world. Because students al- 
ready possess fundamental knowledge of Google Earth, starting by using this program is easier. Because companies like Google dominate the software market, other options for the use in class are often not even considered. Above all it is difficult for other providers to keep pace with global companies when it comes to functionality and user comfort. A student complained during the orientation phase at the start of the project that the Vorarlberg Atlas "doesn't even have a routing function" (original quote of a student, translated into English). Students automatically evaluate every product in comparison with Google products, whereby for example a routing function serves as a measure of quality. Because the province atlases are programs tailored to the needs of the province governments, some functions that students perceive as essential are missing. On the other hand, the numerous additional geodata, for example the information concerning land use, the cadastre, nature preserves, or natural hazard zones, offer a variety of possibilities in the subject of Geography and Economics to not only observe, but also analyse and evaluate spaces from different points of view. The skill to work goal oriented with geodata also strengthens the personal competence to participate in political decisions concerning relevant spatial issues. The route of a planned street project or the intended location of a shopping centre are two concrete examples of real and current issues in Vorarlberg that can be dealt with in classroom using the Vorarlberg Atlas. SCHULZE et al. $(2014,230)$ speak of "emancipated spatial citizens" in this context, and name the ability to work with digital GM as a prerequisite.

\subsection{Interpretation and Presentation of the Results}

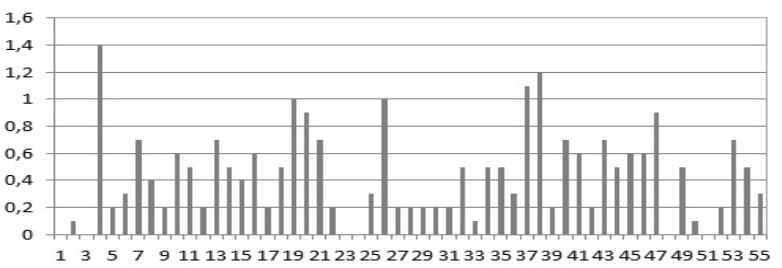

\section{Fig. 2:}

Deviation of the personal evaluation from the class average (created by student Samuel Haim)

The interpretation of the research results is concentrated around two aspects. On the one hand the deviation of the individual evaluation of the "factor of well-being" from the arithmetic average of the class, and on the other hand the connection between the conveyed "factor of well-being" and the frequency of presence. Students should reflect why they evaluated certain areas as better or as worse than the majority of the class. In addition, every student had to create a bar graph (figure 2), using Microsoft Excel, showing the deviation for every investigated area of their individual "factor of well-being" from the mathematical average. In this project there are areas, which nearly all the students evaluated identically, while other investigated areas are evaluated very differently. This is to make clear to them that a statistical average has no real validity about the opinions of individuals.

By comparing the two maps the students created, it should be apparent that the emotional evaluation of space also influences personal conduct in that space. In some parts there is a clear connection between the evaluations of these areas as well as the frequency of presence. Of course in comparison to Vienna (cf. e.g. SCHAUPPENLEHNER et al. 2014), a small town like Feldkirch has no absolute "No Go Areas" for the students. Nonetheless there are certain alleys and squares that are to be avoided, if possible. On a scale from 1 to 4 the investigation areas 44 (3.9) and 39 (3.8) are given the worst rating, and were frequented 
below average, although these investigation areas offer a potential path from the school to the city supermarket. However, it is apparent that there are also spaces that the students frequently visit, in spite of not feeling entirely comfortable in them. An example is the investigation field 5, a central underpass to the important hub of public transportation. It was given a 3.8, the second worst rating, but an above average visitation frequency because there is no reasonable alternative route.

The opportunity to present the findings to the manager of city planning, the city architect and the business manager of the city marketing was a worthy conclusion to the project. The students then worked out concrete suggestions to improve investigation areas with a lower "factor of well-being" rating. Suggestions ultimately regarded improvements with the lighting situation in the underpasses, as well as an improvement in the cleanliness of some investigation areas. In connection to the topic cleanliness, the students also recognized that the behavior of every individual has an influence on the quality of life in town and that the responsibility for a high quality of life rests not solely in the hands of the city government. While the problem of social periphery groups was thoroughly discussed during the project, it was only mentioned briefly in the presentation. As they later mentioned, it became clear to them that there is no easy solution for this problem. Following their presentation, the city architect gave a short overview of the next planned renovations in the city center. It was interesting for both the city officials as well as the students to see that these new renovation projects have a strong correlation to the investigation areas the students rated poorly. As the students and the city officials share the same view as to which problematic areas are to be improved, the students get the impression that their requests are being taken seriously.

\section{Conclusion and Outlook}

\section{Selected Feedbacks from the students about the project, translated into English. Writ-} ten feedback from: 13.06.2014.

"I think this project is meaningful and practical because we are able to present it and maybe even help to make a difference with the issues we raised."

"To work with this class is stressful because everyone is not equally committed. This project was a lot of fun and I am really looking forward to presenting our project to the city services."

\section{"I learned how one works with maps using a computer (Vorarlberg Atlas)"}

The concrete realization of this kind of topic with the help of precise tasks allows the students to work independently and according to their own individual pace. Above all, tasks requiring the use of computers clearly highlight the different working speeds of each student. Therefore, faster working groups need to be occupied with appropriate additional tasks. A big challenge for the realization of a WebGIS project is implementing the necessary technical resources in schools. Next to the requirement to have access to a computer room during a lesson, an entire class working with the Vorarlberg Atlas requires a large data capacity from the school internet connection.

The realization of this very comprehensive project is only possible in the given time when the students are already used to working independently. Through the interpretation of both maps, as well as by working out possible suggestions for improvement, the students are able to gain much valuable insight into the topic of quality of life in public spaces as well as 
their own spatially oriented behavior. In comparison to working with Google Earth or Scribble Maps, working with the provincial atlases requires a somewhat longer orientation phase for the students, whereby the central functions can be conveyed in approx. 30 minutes. On the other hand, there are much more diverse possibilities for use in the classroom. The Vorarlberg Atlas can also be used in various ways in smaller projects from the $8^{\text {th }}$ to $12^{\text {th }}$ grades, according to the personal experience of the author. With relation to the competency raster in Geography and Economics (cf. KELLER \& SCHOBER 2012), it is possible to create tasks using maps at the competence level 2 as well as at the competence level 3 . In order to increase the awareness of these possibilities amongst Geography and Economics teachers, it seems necessary to offer further training seminars in this area.

The target to provide teachers with the necessary skills for their work in classroom with Web 2.0-based digital GM in general is, for example, part of the SPACIT (www. spatialcitizenship.org) project (cf. SCHULZE et al. 2014). In their suggestion for a "Curriculum for Spatial Citizenship Education" for teacher education VOGLER et al. $(2014,368)$ specify the necessary "Fields of Learning and Learning Outcomes for Spatial Citizenship" in which "the utilization of GM" is one target.

Through the intensive work of the students using the Vorarlberg Atlas at the $8^{\text {th }}$ grade level it seems that the realization of smaller projects using professional Desktop-GIS software with these students is realistic in the following years. The government services of Vorarlberg have switched to the Open Source Software QGIS, and support the application of the very complex software through the Department of Geoinformation. So at least two (free access to data and software) out of eight main criteria for the use of GIS in schools named in a study by HöHNLE et al. (2014) should no longer be a problem. Rather, the complexity of professional GIS solutions will remain the main obstacle.

\section{References}

Boeckler, M. (2014), Neogeographie, Ortsmedien und der Ort der Geographie im digitalen Zeitalter. Geographische Rundschau, 6/2014, 4-10.

BORZNER, M. (2013), Disparitäten in Deutschland. Eine GIS-gestützte Unterrichtsreihe zur Förderung der Kartenkompetenz. Praxis Geographie, 10/2013, 38-42.

Buchroithner, M. \& Gartner, G. (2013), The New Face of Cartography. Why cartography is relevant, attractive and contemporary. GIM Internat., 6, 2013, 22-27.

Coleman, D. J., Georgiadou, Y. \& Labonte, J. (2009), Volunteered Geographic Information: the nature and motivation of produsers. International Journal of Spatial Data Infrastructures Research. Special Issue GSDI-11. http://drupal.gsdi.org/gsdiconf/gsdi11/papers/pdf/279.pdf (21/03/2015)

GRAHAM, M. \& ZOOK, M. (2014), Argumentierte Geographien: Zur digitalen Erfahrung des städtischen Alltags. Geographische Rundschau, 6/2014, 18-25.

GRYL, I. \& JEKEL, T. (2012), Re-centering GI in secondary education: Towards a spatial citizenship approach. Cartographica, 47 (1), 18-28.

GRYL, I. (2010), Mündigkeit durch Reflexion. Überlegungen zu einer multiperspektivischen Kartenarbeit. GW-Unterricht, 118, 20-37.

HWANG, S. (2013), Placing GIS in sustainability education. Journal of Geography in Higher Education, 37 (2), 276-291. 
Henning, S. \& Vogler, R. (2011), WebMapping: Der Einsatz von digitalen, interaktiven Karten in Schule und Bildung. GW-Unterricht, 123, 86-99.

Hermes, A., De Lange, N. \& Plass, C. (2011), Multimediale Exkursionsprotokolle mit Geotagging. Praxis Geographie, 11/2011, 36-40.

Höhnle, S., Mehren, R. \& Schubert, J. C. (2014), Criteria Regarding Software and Data for a Successful Implementation of GI(S) in the Geography Classroom. Selected Results from Group Discussions with Geography Teachers in Germany. In: VoGLER, R., CAR, A., Strobl, J. \& Griesebner, G. (Eds.), GI_Forum 2014. Geospatial Innovation for Society, Wien, ÖAW, 318-327.

KANWISCHER, Y. (2014), Digitale Geomedien und Gesellschaft. Zum veränderten Status geographischen Wissens in der Bildung. Geographische Rundschau, 6/2014, 12-17.

KELLER, L. \& SCHOBER, A. (2012), Geograffiti 2. Westermann, Wien, 6-7.

MAREK, A. (2009), Kritischer Umgang mit Karten. Praxis Geographie, 11/2009, 21-25.

MAteI, S., BALl-Rokeach, S. \& QIU, L. J. (2001), Fear and Misperception of Los Angeles Urban Space. A Spatial-Statistical Study of Communication-Shaped Mental Maps. Communication Research, 28 (4), 429-463.

http://mentalmap.org/files/matei_fear_CR.pdf (05/06/2014).

NoLD, C. (2009) (Ed.), Emotional Cartography. Technologies of the Self. http://emotionalcartography.net/EmotionalCartography.pdf (05/06/2014).

OBERrAUCH, A. \& Keller, L. (to be published 2015), „Mapping urban emotions“ - emotionale Raumwahrnehmung kartieren und reflektieren. In: GRYL, I. (Ed.), Methoden. Westermann, Braunschweig.

Presner, T., Shepard, D. \& Kawano, Y. (2014), Hypercities Thick Mapping in the Digital Humanities. Havard University Press. http://escholarship.org/uc/item/3mh5t455\#page-3 (20/03/2015)

SchaupPenlehner, T., Eder, R., HöGlHammer, A. \& Muhar, A. (2014), Transforming Spaces: A Framework for the Identification and Analysis of Adolescents' No-Go Areas in Vienna. In: Vogler, R., CAR, A., Strobl, J. \& Griesebner, G. (Eds.), GI_Forum 2014. Geospatial Innovation for Society, Wien, ÖAW, 276-284.

ScheriaU, H. (2007), Geoland.at - ein Web-GIS Portal für den Unterricht? JeKEL, T., Koller, A. \& Strobl, J. (Eds.), Lernen mit Geoinformation II. Wichmann, Heidelberg, 78-87.

SCHMidT, M. \& KlETTNER, S. (2012), Emotionen zum Raum und deren Berücksichtigung in Navigationssystemen für FußgängerInnen (Projekt EmoMap). http://www.walkspace.at/infomail/NLSA_2011_EmoMap.pdf (05/06/2014).

Schulze, U., GRYL, I. \& KANWISCHER, D. (2014), Spatial Citizenship: Creating a Curriculum for Teacher Education. In: Vogler, R., CAR, A., Strobl, J. \& Griesebner, G. (Eds.), GI_Forum 2014. Geospatial Innovation for Society, Wien, ÖAW, 230-241.

SPACIT. http://www.spatialcitizenship.org/ (18/03/2015).

SITTE, C. (2008), Google-Earth und andere Anwendungen im Unterricht. BM:UK (Ed.), Wissenschaftliche Nachrichten, 133, Wien.

TURNER, A. (2006), Introduction to Neogeography. O'Reilly Media (e-book).

VOGLER, R., KOLLER, A. \& JEKEL, T. (Eds.) (2014), Learning with Geoinformation. Appendix: A Curriculum for Spatial Citizenship Education. GI_Forum 2014. Geospatial Innovation for Society, Wien, ÖAW, 362-380.

VORARLBERG ATLAS. http://vogis.cnv.at/atlas/init.aspx (20/03/2015). 